\title{
Assessment of the potential for modal shift to non-motorised transport in a developing context: case of Lima, Peru
}

\author{
Adriana Ortegon Sanchez, Daniel Oviedo Hernandez \\ University College London, Gower Street, London, WC1E 6BT, UK
}

\begin{abstract}
Developing cities are increasingly pursuing initiatives supporting modal shifts toward sustainable modes of transport, aiming to achieve reductions in adverse environmental impacts associated to transport. Under the logic of Avoid, Shift, Improve, fostered by donors and NGOs worldwide, cities in developing countries are investing emphatically on non-motorised facilities and policies for low-carbon mobility. Such is the case of Lima, Peru, our case study. Through the analysis of the potential for integration of non-motorised facilities with current and planned public transport networks we seek to provide evidence on the planning considerations of non-motorised facilities in Lima with emphasis on multi-modal travel and integration of non-motorised infrastructure. We develop spatial coverage, capacity and accessibility assessment of the 'supply side' of the transport network. In addition, the research emphasises on the identification of trips with potential to non-motorised alternatives based on the local transport system and travel patterns and needs. Based on these analysis we estimate indicators of potential coverage, changes in mobility patterns and distributional effects of current investments. Our analysis suggests that pedestrian coverage of high-capacity public transport can be increased in over 6 times if integrated adequately with cycling facilities. The research provides methodological and empirical contributions to debates related to the capacity of cities in the global south for adopting low-carbon mobility in the foreseeable future.
\end{abstract}

\section{Introduction}

Developing cities are increasingly pursuing initiatives supporting modal shifts toward sustainable modes of transport, aiming to achieve reductions in adverse environmental impacts associated to urban mobility. Under the logic of Avoid, Shift, Improve, fostered by donors and NGOs worldwide (Tiwari et al., 2011) (Dalkmann and Brannigan, 2007), cities in developing countries are investing emphatically on nonmotorised facilities and policies for low-carbon mobility. Such is the case of the Metropolitan Area of Lima, Peru.

This paper examines the potential for integration of modes of transport for the Metropolitan Area of Lima, which includes the Municipalities of Lima and Callao. Such examination stems from the premise that all existing transport modes play different and complementary roles in the current mobility of the city (Rietveld, 2000). In the light of rising concerns with sustainable development, the need for increasing access to opportunities and services for urban populations is constrained by the need for reducing emissions of greenhouse gases. In this context some strategies, as promotion of non-motorised travel, are regarded as more efficient than others to respond to mobility needs (Litman, 2006).

The concept of transport integration and multi-modal travel is not necessarily a new concept (Kenyon and Lyons, 2003). All urban trips, especially those made on public transport, involve a segment (i.e. between the door and the vehicle), to be completed on foot. This means that apart from walking trips, all 
urban travel is, by definition, multimodal. However, integration and multimodal transport is challenged by costs associated to interchanges and the valuation, either positive or negative, that users have of such costs. The latter depends on the convenience and ease associated with making the transfer as well as the impact on the overall trip (e.g. percentage of travel time invested in the transfer). In most cases of integration between modes "on-foot" and private vehicle, the cost of the transfer seems negligible to the point that most people would not consider this as an intermodal journey. However, under the assumption that this is an intermodal trip with at least one transfer, this perceived cost can be explained by the existence of urban facilities that make this integration convenient and comfortable. Transfer costs are drastically reduced through provision of large supply of parking facilities at very short distances from the point of origin and destination and at a relatively low or non-existent price.

Non-motorised modes generally have an environmental impact close to zero and have complete flexibility in terms of timetables and route design but are not suitable for long distances (Walsh et al., 2008; Giles-Corti, 2010). In contrast, mass transit modes are rigid in both the layout of the routes and their operation, but they have a very good performance for medium and long distances and low environmental impact per user, depending on the technology. Hence the importance for a city like Lima, which has a large range of modes, to create a system of integrated transport modes that covers $100 \%$ of the travel demand of the city with good quality service (affordable, accessible and convenient). In Lima, the challenge to promote sustainable mobility relates to definition of conditions of transport planning and urban design to ensure comfort and ease of transfer between the different modes of transport, public and private, to construct an integrated public transport system. The objective is to provide conditions for affordable, convenient and enjoyable door-to-door trips, reducing, whenever possible, monetary costs (public transport fares) and time, and improving comfort.

Given the potential of fostering non-motorised infrastructure as a measure to mitigate environmental impact and positively impact urban development, our research focuses primarily on identifying the integration potential of non-motorized trips (bicycle and walking trips) with mass transit modes (metro system and bus rapid transit system). We build on data from the household mobility survey conducted as part of the update of the city's Urban Transport Master Plan (JICA, 2012). A geospatial analysis of the survey data was conducted in specific nodes or geographic areas of the city where various modes of transport are operating simultaneously without integration. Subsequently, other conditions associated with transport supply, demand and land use characteristics were analysed under a multi-dimensional framework for assessment of the current potential for integration, as well as the constrains and opportunities for its consolidation and expansion.

\section{Objectives and Methodology}

The aim of this research is to identify the areas in the municipality of Lima and Callao that have characteristics that potentially can favour or ease the physical integration of mass public transport modes and non-motorized modes. We define physical integration as "seamless" trips with physical infrastructure that facilitate transfers between modes. To identify the potential for integration we will construct a multidimensional analysis (Zuidgeest, et al., 2009) to define a general characterisation of Lima's transport network infrastructure, its travel patterns and trip segments and its urban services to determine a preliminary typology of integration points or areas.

Our analyses build on secondary databases that include the 2012 Origin-Destination survey for the city of Lima, geo-statistical information of the transport network, non-motorised infrastructure, land-use and socioeconomic figures. 


\subsection{Lima's Transport Planning Context}

For a decade, the transport system of the Metropolitan Area of Lima has experienced significant changes in its structure, organization and services. In particular, higher capacity modes (Metropolitano BRT Line- and the first metro line) were implemented recently. During 2011-2014 the administration of the Metropolitan Municipality of Lima started the process of reorganization of the transport services operating on the city's principal transport axes. This reorganization defines corridors of different hierarchies as well as different types of routes which are meant to be integrated with the high capacity lines of the BRT and the Metro system to complement the service. By mid-2014 measures to improve the service in one medium-capacity corridor were implemented with mixed positive and negative outcomes in terms of quality of service and customers satisfaction. Nonetheless, these new measures are initial steps of the gradual implementation of an Integrated Transport System (ITS) for the city. In addition to this other projects are being developed to improve pedestrian mobility, organize and regulate taxi services, improve traffic flow conditions for private vehicles and to support cyclists' mobility.

The context of the Municipalities of Lima and Callao presents both opportunities and challenges for further development and implementation of initiatives to promote the use of non-motorized transport. In principle, the positive aspects include: i) favourable topography as the city main geographic area is on a plain; ii) favourable weather without extreme temperatures and limited rainfall throughout the year, iii) average trip distance (all modes and purposes) of around $7.5 \mathrm{~km}$ according to the Urban Transport Masterplan and iv) $29.9 \%$ of households own a bike compare to only $16.5 \%$ which owns a private vehicle (ENAHO), v) $126 \mathrm{~km}$ of cycle ways already in place by 2013 and available cycle parking located inside or in vicinity of the BRT system stations and inside three of the metro line stations. However, the negative aspects are related to the fact that low income population will not perceive the mentioned benefits as they inhabit mostly the areas on the hills of the city periphery, which means that their trips are likely to be much longer than average, with segments on steep roads and without adequate infrastructure for non-motorized modes. In the areas where there is available infrastructure there are problems like poor connectivity, lack of maintenance (in the case of cycle ways and sidewalks) or limited access (in the case of cycle parking). Moreover, despite the mild temperatures because of the limited amount of greenery to provide natural shadow, sun exposure can be perceived by users as a barrier for using non-motorized modes during the warmest months.

\subsection{Methodology}

The integration potential assessment for Lima's transport system was done using data from the 2012 Household Transport Survey and geo-referenced data of the city's public transport system infrastructure. In order to identify the areas with greatest potential for improving the integration of sustainable transport modes in Lima and Callao three key aspects were analysed: (i) Coverage and connectivity of transport system infrastructure (transport system supply), ii) Trips generation and attraction between Traffic Analysis Zones (TAZ) (transport system demand), iii) Distribution of urban services and access to activities. For the analysis of local non-motorized (walking and cycling) trips and the detail design of measures a higher level of disaggregation might be appropriate. However, for purposes of this city-wide comparative analysis of areas around the city, the TAZ represent a manageable scale. In addition, most of the available information has this level of aggregation which facilitates the standardization of the analysis across different data sources.

Based on the analysis of the technical information gathered, the modes with potential for integration were identified. The main objective of this research is to understand conditions under which Lima's transport system could be used more efficiently in order to reduce the greenhouse gas emissions. Hence, the analysis focuses primarily on the integration of non-motorized modes, the mass transit systems (Metro and Metropolitano -BRT line- in Lima) and traditional public transport (such as buses, taxis and 
motorcycle-taxis). The analysis focuses mainly on the integration of mass transit with non-motorized modes. Nonetheless, the analysis also considers the integration of mass transit modes and conventional buses, taxis and motorcycle-taxis, based on the potential modal shift from these modes to non-motorized modes for short (feeder) trips. Table 1 present the complete list with the variable per category.

\begin{tabular}{|c|c|c|}
\hline DIMENSION & & VARIABLE \\
\hline \multirow{4}{*}{ Demand } & D1 & Short walking trips attracted to the TAZ (less than $5 \mathrm{~km}$ ) \\
\hline & D2 & Short cycling trips attracted to the TAZ of less than $5 \mathrm{~km}$ \\
\hline & D3 & Short taxi and motorcycle-taxi trips attracted to the TAZ (less than $5 \mathrm{~km}$ ) \\
\hline & D4 & Short conventional buses trips attracted to the TAZ (less than $5 \mathrm{~km}$ ) \\
\hline \multirow{9}{*}{ Infrastructure } & I1 & Density of cycle lanes per km of roads within the TAZ \\
\hline & $\mathrm{I} 2$ & Coverage of Metro Line $1(400 \mathrm{~m})$ \\
\hline & I3 & Coverage of BRT Metropolitano (400 m) \\
\hline & I4 & Coverage of Metro Line (3 km) \\
\hline & I5 & Coverage of BRT Metropolitano (3 km) \\
\hline & I6 & Coverage of Metro Lines 2 and 4 (400 m) \\
\hline & I7 & Coverage of Metro Lines 2 and $4(3 \mathrm{Km})$ \\
\hline & I8 & Coverage of cycle parking \\
\hline & I9 & Coverage of cycle lanes (400 m) \\
\hline \multirow{9}{*}{ Urban Services } & U1 & Land-use types and conditions for non-motorised travel \\
\hline & $\mathrm{U} 2$ & Supply of work-related activities \\
\hline & U3 & Supply of education-related activities \\
\hline & U4 & Supply of leisure activities \\
\hline & U5 & Population within area of influence of BRT Metropolitano $(400 \mathrm{~m})$ \\
\hline & U6 & Population within area of influence of BRT Metropolitano $(3 \mathrm{~km})$ \\
\hline & U7 & Population within area of influence Metro Line 1 (400 m) \\
\hline & U8 & Population within area of influence Metro Line 1 ( $3 \mathrm{~km})$ \\
\hline & U9 & Population within area of influence Metro Line 2 and 4 (3 km) \\
\hline
\end{tabular}




\begin{tabular}{|l|c|l|}
\hline & U10 & Population within area of influence of cycle lanes \\
\cline { 2 - 3 } & U11 & Population within area of cycle parking \\
\hline & U12 & Rate of cycle ownership \\
\hline
\end{tabular}

Table 1. Variables per Dimension for TAZ Integration Potential Analysis

\section{Results}

Building on literature concerning accessibility and environmental assessment of transport investments, we developed a set of indicators for identifying the main features and challenges of present non-motorised network of Lima and priorities for integration. We develop spatial coverage, capacity and accessibility assessment of the 'supply side' of the transport network. In addition, the research emphasises on the identification of trips with potential to non-motorised alternatives based on the local transport system and travel patterns and needs. Based on these analyses we estimate indicators of potential coverage, changes in mobility patterns and distributional effects of current investments in urban transport development both motorised and non-motorised.

\subsection{Coverage and connectivity of transport system infrastructure}

The first analysis of the system's coverage was done for pedestrians in the catchment area of mass transit lines (Metropolitano -BRT line- and Lima Metro line 1), with coverage up to 400 meters (pedestrian coverage) the potential beneficiaries are of about 710,000 people, or about $7 \%$ of the estimated population for the Metropolitan area of Lima and Callao; whereas with coverage of up to $3 \mathrm{~km}$ (cyclist coverage), about 3.8 million people are estimated as potential beneficiaries having potential access to at least one of the two mass transit lines and about 2 million people having access to both lines. A comparative analysis of the potential demand within the pedestrian coverage (710,000 people) and the cycling coverage (3.8 million people) shows that by incorporating facilities for cycling an additional demand of up to 4.3 times the obtained only with a pedestrian coverage can be achieved (about $45 \%$ of the population in the area of analysis). An scenario with Metro lines 2 and 4, operating from east to west (transvers to the existing Metro Line, Line 1), would have a potential population covered of an extra 2.3 million, equivalent to $25 \%$ of the current population of the study area. 


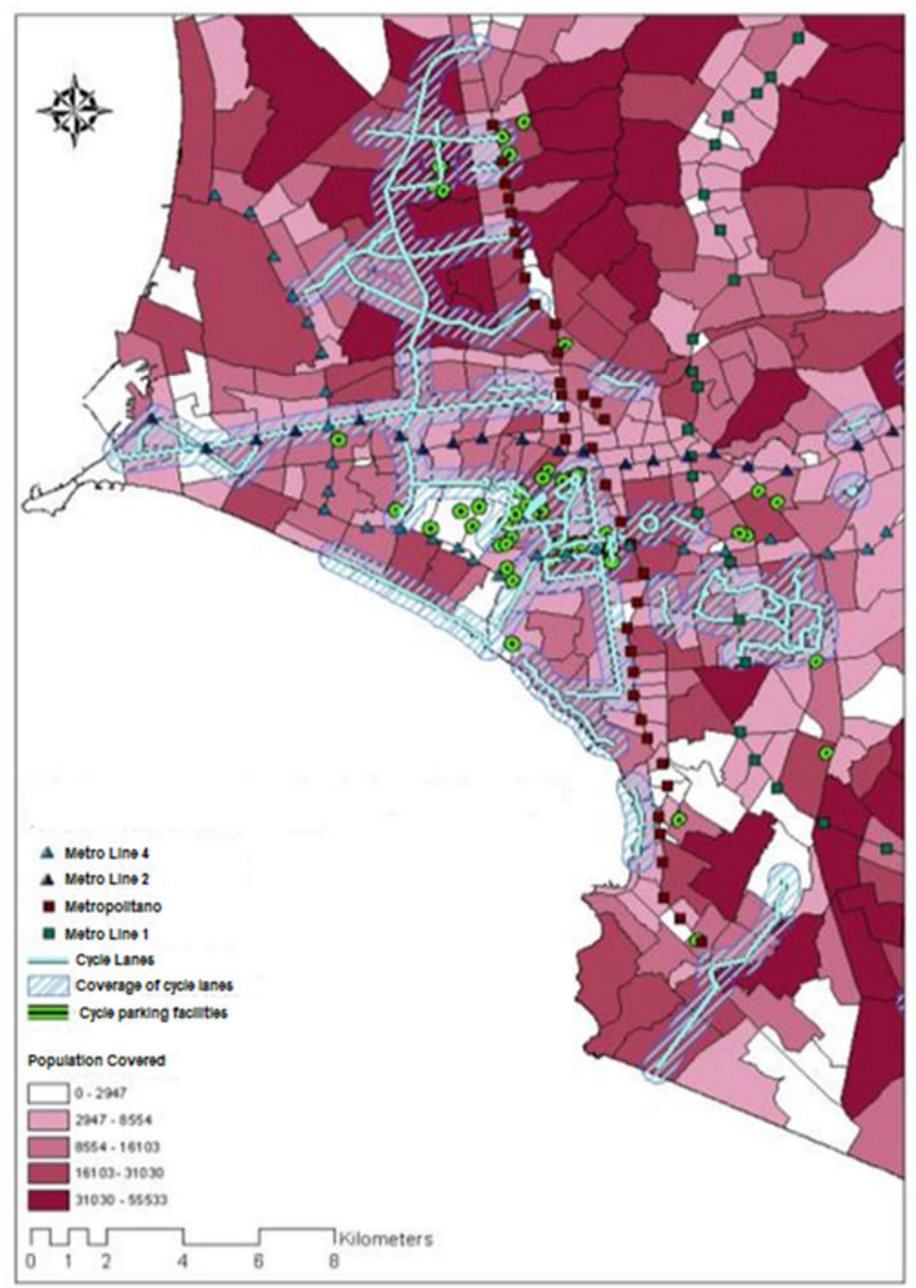

Fig. 1. Metropolitan Area of Lima: Cyclist coverage of current and planned public transport network. Fig. 2. Metropolitan Area of Lima: Population covered by current and planned public transport network 


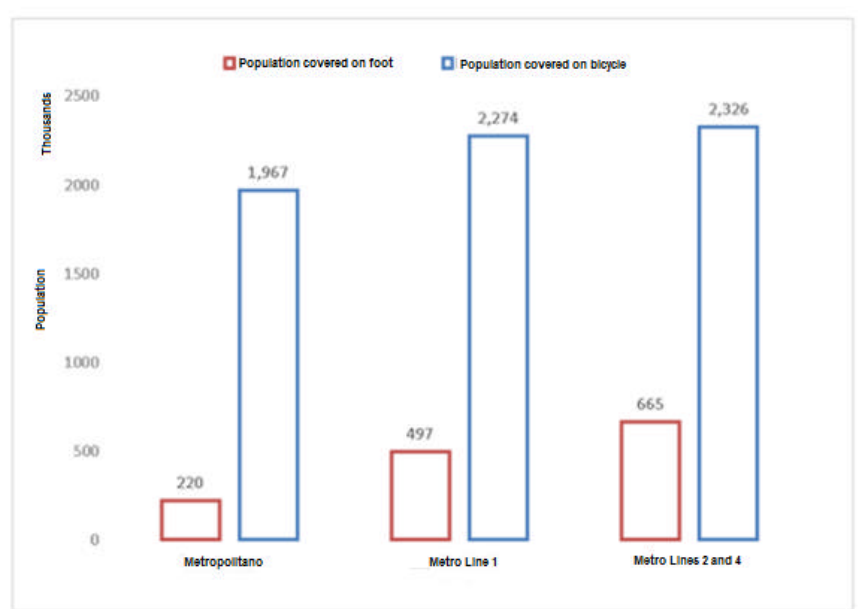

Fig. 3. Metropolitan Area of Lima: Density of Cycle Lanes per ZAT

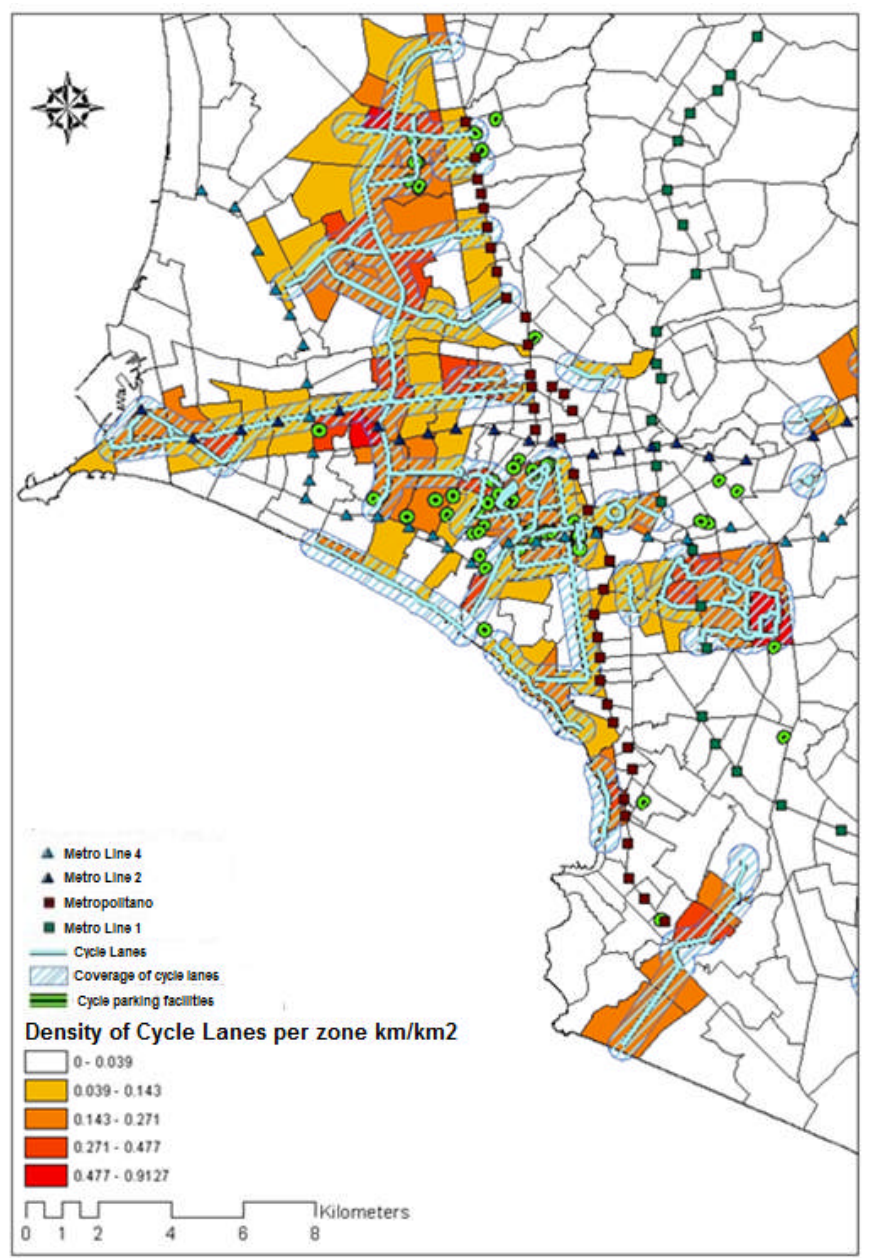

Aside from the spatial coverage indicator for public transport infrastructure, we estimated an indicator of density of cycle lanes by considering pedestrian access to bikeway corridors by TAZ. This indicator allowed us to point out areas of concentration of cycling infrastructure for detailed exploration. As 
evidenced in Figure 3, the main problem of existing bikeways in Lima has to do with connectivity and consistency with patterns of travel attraction and existing and planned network of mass transit.

A complementary indicator of the potential use of existing infrastructure we calculated bicycle ownership per ZAT. This value provides an approximation to the potential of vehicles that could occupy existing infrastructure. Relatively high averages, reflecting considerable tenure averages bicycles, similar to those seen in cities like Bogota or Buenos Aires are observed. The study area has approximately 2.1 million bicycles, according to information obtained from JICA data (JICA, 2012). These figures demonstrate the potential demand in the city to increase the use of bicycles as part of the strategies of travel of citizens of Lima and Callao. However, compared with other capital cities of Latin America, this potential is particularly underused, being Lima the city with less cycle ridership in comparison with other cities of similar scale and importance in their respective countries (Inter-American Development Bank, 2013).

\subsection{Trips generated and attracted by Traffic Analysis Zone}

The results of the 2012 household travel survey shows that only $0.35 \%$ of total trips were made by bicycle, which represents a low share in the modal split throughout the day. The mode 'walking' has an important share of more than $24 \%$ of the daily trips. Public transport modes (mass and conventional) mobilize $49 \%$ of the transport demand of the city. Individual transport modes such as motorcycle and private cars represent about $16 \%$ of total trips. Finally taxi, collective-taxi and motorcycle-taxi have a share of about $10 \%$. From a sustainable transport perspective and considering the relatively low share of private vehicle mobility within the overall modal share, the city could seek to maintain, in the long term, the existing balance between the use of public transport and private transport, focusing on improving public transport, increasing the use of non-motorized modes, especially bicycle and providing safe and secure conditions for the walking trips which in 2012 accrued for almost a quarter of daily trips.

Based on the specific characteristics of the municipality's transport demand, short trips of less than 5 kilometres were defined as the trips that could potentially be done in non-motorized modes. The analysis of trips by mode and distance shows that there are 2.3 million trips of less than 5 kilometres that are currently being made in conventional buses or taxis (including motorcycle-taxi and collective taxi). Moreover, as presented in Figure 5 the geographical analysis of the trip density (normalized by the TAZ area) and the desire lines of trips of less than 5 kilometres suggest that especially trips done by taxis and motorcycle-taxi serve the function of feeders to the mass transport system. This further suggests the suitability of these trips to be shifted to non-motorized modes in order to reduce emissions per passenger. 


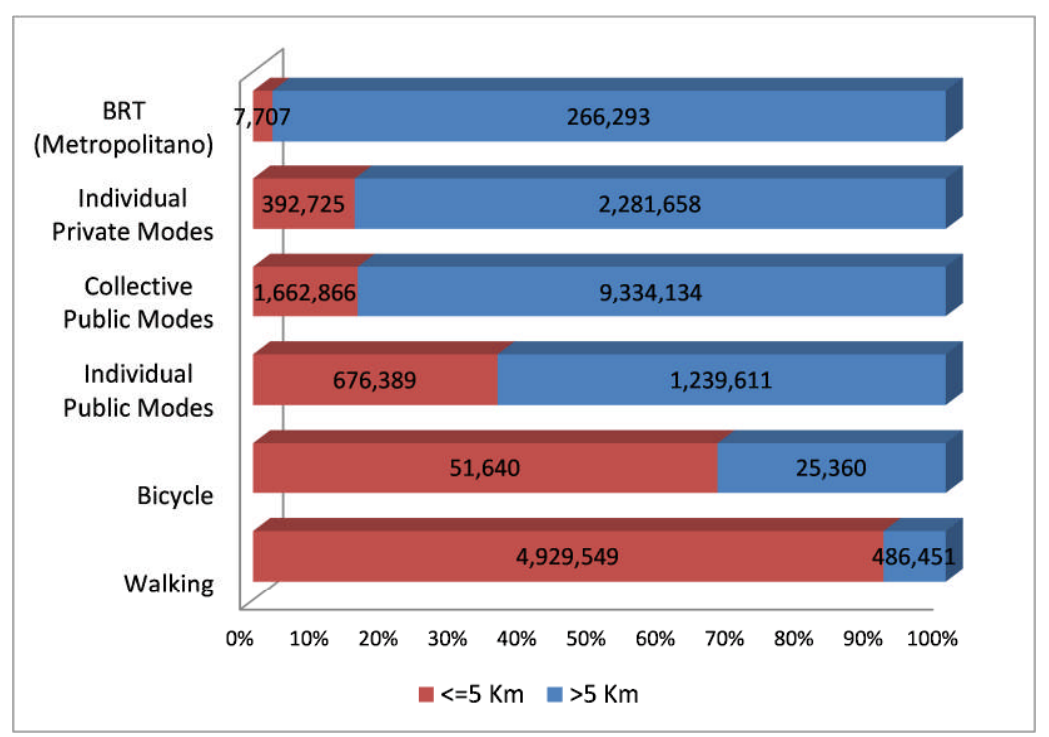

Fig. 4. Total daily trips by modes and $5 \mathrm{~km}$ distance

\begin{tabular}{|l|r|r|}
\hline \multicolumn{1}{|c|}{ Mode } & $\begin{array}{c}\text { Total daily } \\
\text { trips }\end{array}$ & Share \\
\hline Walking & $5,416,000$ & $24.4 \%$ \\
\hline Bicycle & 77,000 & $0.3 \%$ \\
\hline Motorcycle & 107,000 & $0.5 \%$ \\
\hline Motorcycle-taxi & $1,325,000$ & $6.0 \%$ \\
\hline Private car & $3,401,000$ & $15.3 \%$ \\
\hline Taxi & 591,000 & $2.7 \%$ \\
\hline Collective taxi & 333,000 & $1.5 \%$ \\
\hline Combi bus & $3,880,000$ & $17.5 \%$ \\
\hline Micro bus & $5,536,000$ & $25.0 \%$ \\
\hline Ómni bus & $1,248,000$ & $5.6 \%$ \\
\hline $\begin{array}{l}\text { BRT } \\
\text { (Metropolitano) }\end{array}$ & 274,000 & $1.2 \%$ \\
\hline \multicolumn{2}{|l}{} \\
\hline
\end{tabular}

Table 2. Modal share 


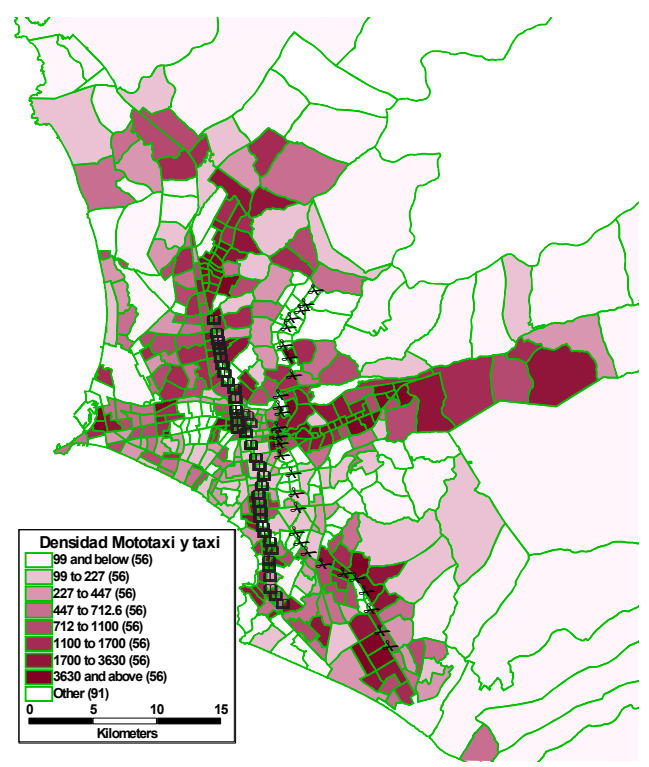

Fig. 5 Motorcycle-taxi and taxi trips density (trips less than $5 \mathrm{~km}$ )

Source: Authors based in travel survey data (JICA, 2012

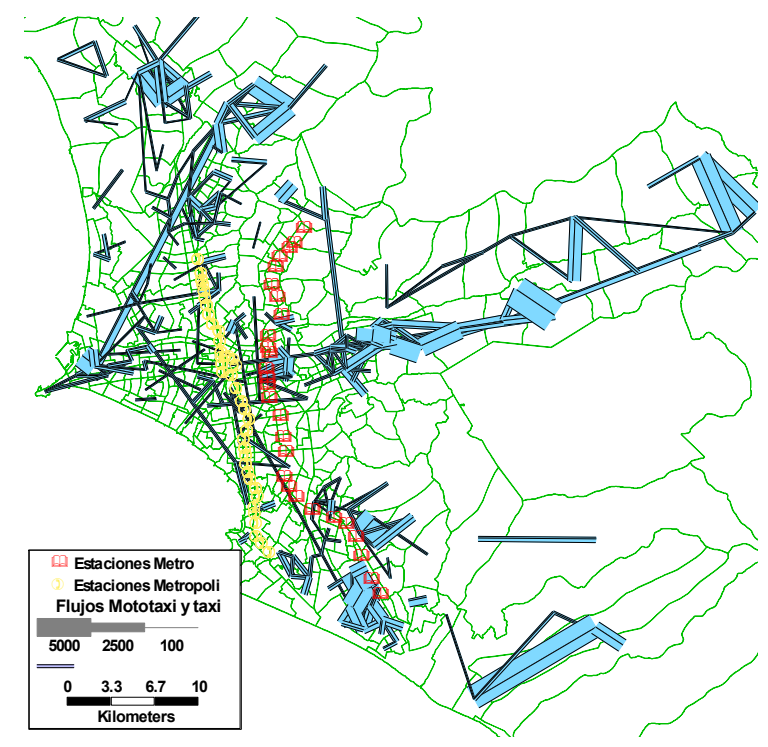

Fig. 6 Desire Lines Motorcycle-taxi and taxi trips (trips less than $5 \mathrm{~km}$ )

\subsection{Distribution of urban services and access to activities}

Besides the transport infrastructure (supply) and demand characteristics, certain urban characteristics, such as the distribution of productive and leisure activities or land-uses, were analysed. The analysis of the location of activities shows that opportunities, activities and services are clustered in the same zones as transport supply and demand. On the other hand, it was observed the most favourable land-uses to facilitate modal integration are those related to retail and business areas with medium or high densities.

The analysis of the location of activities shows that the opportunities, activities and services are concentrated in the same places where supply and demand of transport is. The objective of identifying this location is able to quantify how new infrastructure or equipment can expand the area of influence of the systems and, therefore, increase the accessibility of the population to opportunities. Also, to identify areas with potential for integration, the amount of activities available in the area will be used as an indicator of urban conditions in the area. To that extent, areas with more activities will better assessment when evaluating the potential for integration 


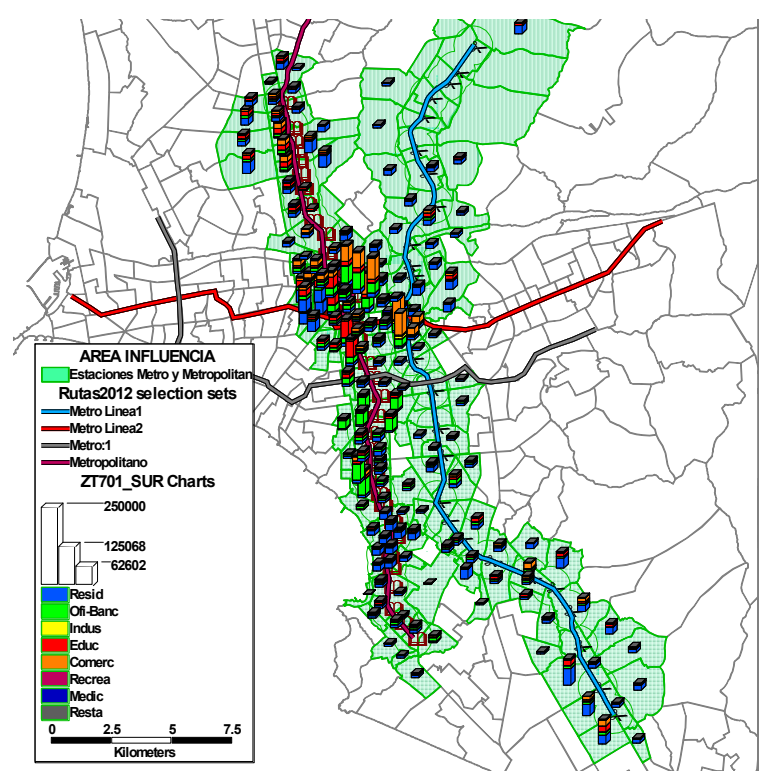

Fig. 7 Activities in the catchment area of Mass transport system (Metro line 1 and BRT corridor)

\subsection{Discussion: Selecting areas for prioritisation}

To identify potential areas of intervention 25 indicators were analysed. The indicators were grouped as follows: four demand indicators (related to the generation - attraction of short zonal trips in public transport -individual and collective- and non-motorized modes), 9 infrastructure indicators (related to the density of bikeways and the coverage of mass transit system), and 12 urban system indicators (related with land-use, population and opportunities' distribution). Considering the three groups of indicators, for each Traffic Analysis Zone (TAZ) an index combining the demand, infrastructure and urban indicators was estimated. Based on the index each TAZ received a score within a ranking system between 1 and 100 , where a 100 represents the areas with greatest potential for integration. The following are the four areas where the potential for intermodality was high -each composed of various TAZ-: Centre, South, East and North. The 4 zones include 6 districts: In the centre Jesús María, Lince, La Victoria and Lima Cercado; in the North Los Olivos area; In the East Ate; and in the South Villa El Salvador. In addition, the district of San Borja was included because, despite of obtaining a low score in the assessment, it has specific characteristics in terms of cycling infrastructure. 


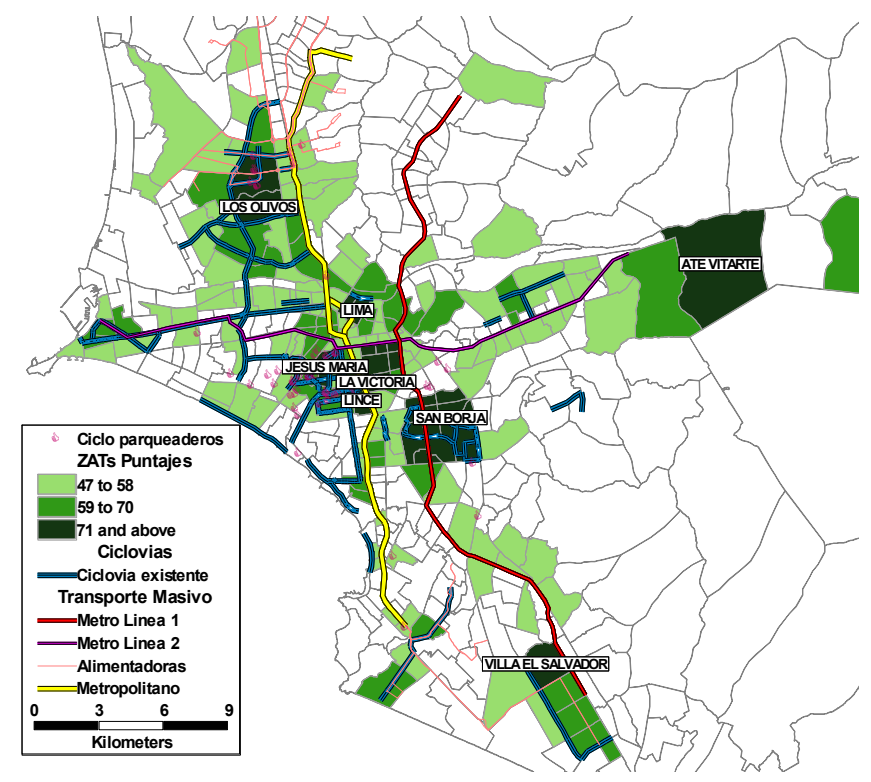

Fig. 8 Areas with Integration Potential

\section{Conclusions}

At first glance the evidence from Lima shows favourable conditions for the first two steps of the Avoid-Shift-Improve strategy for delivering sustainable transport. However, as presented in Figure 4 a large share of public transport demand is served by traditional collective transport which provides a lowquality service with negative environmental externalities. Lima is already investing in improving the mass transport system network through investment in BRT and rail technologies. However the share of those modes is still very low especially because of their large dependency on the informal feeding services, mostly provided with the same obsolete technology that the city is aiming to replace. Therefore measures that support modal integration play a role in the 'improve' step by facilitating the substitution of access trips (feeder trips of less than $5 \mathrm{~km}$ ) done in obsolete modes by non-motorized whilst increasing mass transport ridership increasing the value and benefits generated by the investment made on that infrastructure.

The need for prioritisation of interventions in non-motorised infrastructure with a focus on multi-modal integration is supported partly because of historical approaches to transport financing in Latin America, and specifically on Lima. The focus has been on isolated investments for specific projects but examples of cities worldwide support the idea that to provide city-wide accessibility and increase or maintain the share of sustainable transport modes whilst controlling the share of private vehicles, a multi-modal integrated transport system is needed, mostly because public transport has the most customer appeal and is most efficient when it is planned and operated as a seamless, integrated system.

Assessed on their own the impact of NMT interventions might seem limited in terms of the demand and environmental effects they can bring about if compared to large investments on transport infrastructure. The objective of holistic analysis in the context of an integrated transport system can largely outweigh the costs associated with NMT investments, particularly in relation to their potential for increasing the benefits of large interventions. The assessment of the capacity of integration between NMT and mass transit allows a sensible estimation of additional ridership and connectivity attainable by such systems. 
In this regard, prioritisation of NMT interventions can lead not only to a more-wide spread use of cycling, they can also contribute to better transport planning in cities currently undergoing reforms targeting sustainable transport. As reflected by the evidence of both supply and demand-related indicators, the project-specific approach in cycling investment has led to a fragment cycling network. This has produced an equally fragmented use of the infrastructure, limiting its positive impacts on larger travel, particularly commuting. Results from the integrated assessment give priority to complete connectivity and allow better multi-modal interaction, which will foster benefits for current cyclists and increase the attractiveness for potential users.

The proposed methodology aims to provide a structured way for considering simultaneously the different dimension (Transport infrastructure coverage and connectivity, demand patterns and urban services) that can bring potential benefits or limitations to NMT interventions. Complementary criteria for decision makers is required to consider the standard address demand approach as well as help identifying gaps in the current multimodal structure. This will contribute to better-exploit interventions currently in place and support the functional structure of the city that helps consolidate the conditions for nonmotorized transport and secures long-term sustainability of the benefits of the transport system. The insights of this research can help informing future research on indicators and analysis that can be operationalised in cities with similar conditions for the development of NMT infrastructure as Lima and that face similar constrains in relation to approaches to transport planning, monitoring and financing.

\section{Acknowledgements}

This research is framed within a larger work sponsored by the Deutsche Gesellschaft für Internationale Zusammenarbeit -GIZ- and supported by the government of Lima. The research would have not been possible without the support of GIZ and the local government, which provided the secondary information used as part of the analysis. Additional acknowledgements are given to Professor Nick Tyler, Mariana Alegre and Juan José Arrué who collaborated with the authors in the development of the larger project and provided valuable discussions that enriched the analysis shown in this paper.

\section{References}

Dalkmann, H. and Brannigan, C. (2007) Transport and Climate Change. Module 5e: Sustainable Transport: A Sourcebook for Policy-Makers in Developing Cities. Deutsche Gesellschaft Fuer Technische Zusammenarbeit (GTZ), Eschborn

Giles-Corti, B., Foster, S., Shilton, T., \& Falconer, R. (2010). The co-benefits for health of investing in active transportation. New South Wales public health bulletin, 21(6), 122-127.

Kenyon, S., \& Lyons, G. (2003). The value of integrated multimodal traveller information and its potential contribution to modal change. Transportation Research Part F: Traffic Psychology and Behaviour, 6(1), 1-21.

Litman, T., \& Burwell, D. (2006). Issues in sustainable transportation. International Journal of Global Environmental Issues, 6(4), 331-347.

Rietveld, P. (2000). Non-motorised modes in transport systems: a multimodal chain perspective for The Netherlands. Transportation Research Part D: Transport and Environment, 5(1), 31-36.

Tiwari, R., Cervero, R., \& Schipper, L. (2011). Driving CO 2 reduction by integrating transport and urban design strategies. Cities, 28(5), 394-405. 
Walsh, C., Jakeman, P., Moles, R., \& O’Regan, B. (2008). A comparison of carbon dioxide emissions associated with motorised transport modes and cycling in Ireland. Transportation Research Part D: Transport and Environment, 13(6), 392-399.

Zuidgeest, D. M., Brussel, M., Arora, A., Bhamidipati, S., Amer, S., de Souza, F., et al. (2009). On busbike integration. ADB. Clean Air Initative for Asian Cities. 